\title{
EL PROCEDIMIENTO LEGISLATIVO EN LAS CORTES GENERALES: REGULACIÓN, FASES Y TIPOS
}

\author{
PIEDAD GARCÍA-ESCUDERO MÁRQUEZ \\ Letrado de las Cortes Generales \\ Profesora Titular de Derecho Constitucional
}

\section{SUMARIO}

I. El procedimiento legislativo en las Cortes Generales: fuentes de su regulación.

II. Fases del procedimiento legislativo.

III. Tipos de procedimientos legislativos.

\section{EL PROCEDIMIENTO LEGISLATIVO EN LAS CORTES GENERALES: FUENTES DE SU REGULACIÓN}

Constituye el objeto de este trabajo las fases y tipos que presenta el procedimiento legislativo en las Cortes Generales. Para abordar el objeto de estudio, podemos comenzar identificando las normas en las que se contiene su regulación, que integran el Derecho procesal legislativo español. Según Merkl, el Derecho procesal legislativo (una de las tres grandes ramas del Derecho procesal, junto al judicial y al administrativo), constituye la parte principal del Derecho constitucional y representa la suma de las reglas de producción de las leyes y de otros actos estatales de rango superior o idéntico a las leyes ${ }^{1}$. En la medida en que las Cortes no sólo hacen leyes (no sólo ejercen la potestad legislativa, ex artículo 66.2 CE), el Derecho procesal parlamentario estará integrado por el conjunto de normas que regulan los distintos procedimientos parlamentarios mediante los cuales las Cámaras ejercen sus diferentes funciones. No obstante, si ha de destacarse la importancia de la función legislativa de

1 A. MERKL, Teoría general del procedimiento administrativo, Editora Nacional, México, 1980, págs. 280 y ss. 
las Asambleas, también ha de coincidirse con Merkl en la importancia del Derecho procesal legislativo, aunque sólo constituya una parte del Derecho procesal parlamentario ${ }^{2}$.

\section{I.1. CONSTITUCIÓN}

Encontramos las primeras normas que rigen el procedimiento legislativo en la Constitución, la cual, sin perjuicio de consagrar un título a las relaciones entre el Gobierno y las Cortes Generales, en el que incluye la regulación de los instrumentos de control y responsabilidad, dedica el capítulo central de su Título III ("De las Cortes Generales", arts. 81 a 92) a la elaboración de las leyes, como función nuclear de las Cortes Generales.

Esta regulación constitucional del procedimiento legislativo se produce por primera vez en nuestra historia, siguiendo el ejemplo de las Constituciones de la segunda posguerra mundial ${ }^{3}$. Sería una manifestación más del constitucionalismo racionalizado el elevar a la norma fundamental cuestiones hasta entonces reguladas por otras de nivel inferior o, sencillamente, por la práctica política.

La división del Título III de la Constitución, relativo a las Cortes Generales, en tres capítulos separa los preceptos reguladores de la organización y funcionamiento de las Cámaras (capítulo I, artículos 66 a 80) de los que manifiesta dedicar a la elaboración de las leyes, que supuestamente disciplinarían el procedimiento legislativo (capítulo II, artículos 81 a 92), para luego incluir un tercer capítulo, de tal vez menor justificada coherencia sistemática, referido a los tratados internacionales. Se trata en este caso del ejercicio de otra potestad de las Cortes Generales, diferente de la legislativa (como ha confirmado el Tribunal Constitucional en su sentencia 155/2005), mediante la que se articula su participación (en diferentes grados) en la política internacional, cuya dirección, conforme al artículo 97, compete al Gobierno ${ }^{4}$.

2 En el mismo sentido, S. TOSI (Derecho Parlamentario, M. A. Porrúa, México, 1986, pág. 197): siendo la ley formal el medio de manifestación más solemne del acto político (entendido como expresión de voluntad formalmente imputable al Estado, que lo adopta a través de la aprobación por las dos Cámaras), el análisis del procedimiento de elaboración de la ley es uno de los concretos aspectos más relevantes del ejercicio concreto de la soberanía en un régimen político determinado.

3 Como señala E. AJA FERNÁNDEZ ( La reforma del procedimiento legislativo en el nuevo Reglamento del Congreso de los Diputados", en Las fuentes del Derecho. Primeras Jornadas Jurídicas de Lleida, Universidad de Barcelona, Barcelona, 1983, pág. 81), parece un rasgo común a los textos constitucionales de la segunda posguerra una amplia especificación de las reglas del procedimiento legislativo, sin duda por la importancia creciente de la forma de aprobación de las leyes y la misma complejidad que ha adquirido el ordenamiento jurídico en el Estado actual.

4 No compartimos en este punto la opinión de F. SANTAOLALLA LOPEZ ("Elaboración de las leyes. Comentario al Capítulo II del Título III de la Constitución", en Comentarios a la Constitución española de 1978, dirigidos por O. Alzaga Villaamil, tomo VII, Edersa, Madrid, 1998, pág. 20, y "La Ley y la autorización de las Cortes a los tratados internacionales", Revista de Derecho Político, n. ${ }^{\circ} 11$, 1981, especialmente págs. 45 a 56) de que la tramitación y autorización por las Cámaras de los tratados internacionales no debe diferenciarse esencialmente de los actos legislativos. 
Centrándonos en el contenido del capítulo segundo del Título III, podemos realizar las observaciones siguientes:

a) En primer lugar, no se ocupa este capítulo únicamente de la elaboración de las leyes por las Cortes Generales, pese al Título en que se integra. Por el contrario, gran parte del mismo está dedicado a las normas con rango de ley que aprueba el Gobierno: decretos legislativos (artículos

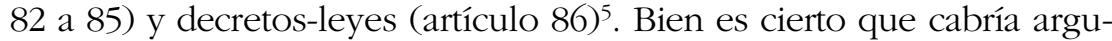
mentar, para defender tal ubicación sistemática, que estos preceptos tratan de la elaboración de leyes (como reza la rúbrica) y que contemplan el ejercicio de facultades de las Cortes Generales que forman parte de su potestad legislativa, en el primer caso la delegación legislativa en el Gobierno, con su correspondiente control (artículo 82.5), y en el segundo la convalidación de la legislación de urgencia.

No obstante, si la intención del constituyente fue regular "la elaboración" (como reza la rúbrica del capítulo) de todas las normas con fuerza de ley, parece que las leyes de aprobación parlamentaria debieran haber sido tratadas en primer lugar y, en todo caso, uniendo todos los preceptos relativos a las mismas, no comenzando por las leyes orgánicas (que aprueban las Cortes Generales) para seguir con las normas con rango de ley cuya aprobación atribuye al Gobierno ${ }^{6}$.

b) En segundo lugar, el capítulo no regula exclusivamente la elaboración de las leyes, sino que incluye cuestiones ajenas, como lo demuestra el artículo 92, dedicado a todo tipo de referendos, ni siquiera sólo al consultivo ${ }^{7}$.

c) Quedan, pues, apenas cinco artículos (81 y 87 a 90) para disciplinar la elaboración de las leyes en el ámbito que les es propio, es decir, para el

5 J. A. SANTAMARÍA PASTOR ("Comentario al artículo 87", en Comentarios a la Constitución, dirigidos por F. Garrido Falla, 3. ${ }^{a}$ ed., Madrid, 2001, pág. 1380), considera que la desconcertante inclusión en este capítulo del artículo 86, que tendría un encaje sistemáticamente más adecuado en el Título V, sólo se explica por un criterio académico de tratar a los decretos-leyes junto con la otra modalidad de disposiciones del Ejecutivo con fuerza de ley, esto es, los decretos legislativos (arts. 82 a 85 ).

6 Entiende I. ASTARLOA HUARTE-MENDICOA ("Perspectivas de modificación del procedimiento legislativo", en El procedimiento legislativo. VJornadas de Derecho Parlamentario, Congreso de los Diputados, Madrid, 1997, pág. 405) que, de hecho, en las escasas reglas sobre el procedimiento de tramitación de las leyes sentadas por la Constitución, bajo el epígrafe del capítulo segundo que examinamos lo que se hace esencialmente es establecer una tipología de leyes a la que, lógicamente, habrán de ajustarse los procedimientos de tramitación.

7 J. A. SANTAMARÍA PASTOR (Comentario al artículo 87", cit., pág. 1380) cree que la asimismo desconcertante inclusión aquí del artículo 92, de todo punto discutible en cuanto al referéndum consultivo sobre decisiones políticas de especial trascendencia (lo que cabe extender con más razón, a nuestro juicio, a las distintas modalidades de referéndum aludidas en el apartado 3 del artículo 92), no guarda relación alguna con el procedimiento legislativo y tiene su explicación en la mera inercia, ya que las primeras versiones del actual artículo 92 regulaban el referéndum ratificatorio de leyes aprobadas por las Cortes Generales (pero no sancionadas) y el de derogación de leyes ya vigentes. 
procedimiento legislativo en las Cortes Generales. Y aun de ellos, excluyendo el artículo 91, los tres primeros (87-89) se refieren a la iniciativa legislativa (sus diversos tipos, la iniciativa gubernamental y la parlamentaria) y el 91 a la sanción real: actuaciones todas ellas, salvo la contemplada en el artículo 89, que no tienen lugar en sede parlamentaria y respecto de las que se discute si forman o no parte del procedimiento legislativo. En todo caso, ajenas a nuestro objeto de estudio.

¿Quiere decirse, pues, que del capítulo dedicado a la elaboración de las leyes, sólo el artículo 81, relativo a las leyes orgánicas, y el 90, con la salvedad de lo que se diga sobre el artículo 89, regulan el procedimiento legislativo en sentido estricto? Parece que la respuesta ha de ser afirmativa, con la inmediata conclusión de que tal regulación dista mucho de ser exhaustiva, puesto que el artículo 90 únicamente regula la intervención del Senado en el procedimiento.

Pero de un cuidadoso rastreo del texto constitucional llegamos a una segunda conclusión: existen algunos otros preceptos de la Constitución que han de ser tenidos en cuenta al exponer la normativa que rige el procedimiento legislativo. Dada la falta de exhaustividad y de sistemática de la regulación constitucional, intentaremos hacer un mero listado de los preceptos constitucionales que afectan al procedimiento legislativo:

\section{Preceptos que afectan a la iniciativa legislativa}

- el artículo 87 regula los diferentes titulares de la iniciativa legislativa.

- el artículo 88 se refiere a la iniciativa legislativa del Gobierno.

- el artículo 89 remite la tramitación de las proposiciones de ley a su regulación por los Reglamentos.

2. Preceptos relativos al procedimiento legislativo ordinario

- el artículo 89.1 establece la prioridad de los proyectos de ley (con la limitación que formula a continuación) y remite, como se ha dicho, a los Reglamentos de las Cámaras la regulación de la tramitación de las proposiciones de ley.

- el artículo 89.2 prescribe la tramitación de las proposiciones de ley tomadas en consideración por el Senado.

- el artículo 90 prevé la intervención del Senado en el procedimiento legislativo.

- el artículo 134.6 establece una especialidad de tramitación para las enmiendas y proposiciones que supongan aumento de los créditos o disminución de los ingresos presupuestarios.

3. Preceptos que contemplan variantes abreviadas o especialidades en el procedimiento legislativo ordinario (volveremos sobre esta cuestión al tratar de los tipos de procedimiento legislativo).

- el artículo 75 sienta las bases de la delegación legislativa en las comisiones permanentes legislativas y, por tanto, de un procedimiento legislativo regulado como especial en los Reglamentos, aunque nos reservamos nuestra calificación para más tarde. 
- el artículo 90.2 establece los efectos que en el procedimiento legislativo en el Senado produce la declaración de urgencia.

4. Preceptos que contemplan procedimientos especiales para la aprobación de determinadas leyes

- el artículo 81 define a las leyes orgánicas por la materia a la que afectan y por el procedimiento especial de elaboración que establece.

- el artículo 134 regula las especialidades de tramitación del proyecto de Ley de Presupuestos Generales del Estado.

- el artículo 150, tras referirse al contenido, que no al procedimiento (salvo la exigencia de ley orgánica para las segundas) de las leyes marco, de transferencia y delegación, establece la exigencia de apreciación por las Cámaras de la necesidad de dictar leyes armonizadoras, como requisito previo a su tramitación.

- los artículos 146, 147, 151 y 152 regulan la aprobación de los Estatutos de autonomía.

- el artículo 74.2 establece un procedimiento especial para la aprobación del Fondo de Compensación Interterritorial previsto en el artículo 158.2, cuya tramitación se inicia en el Senado y, en caso de desacuerdo entre las Cámaras, concluye con la intervención de una Comisión mixta paritaria, de forma similar a lo previsto para la autorización de tratados internacionales y de convenios entre Comunidades Autónomas 8 .

5. Precepto regulador de la sanción, promulgación y publicación de las leyes aprobadas por las Cortes Generales: artículo 91

6. Otros preceptos que contienen normas que afectan al procedimiento legislativo

8 Sobre la tramitación de este proyecto de ley, véase P. GARCÍA-ESCUDERO MÁRQUEZ, $L a$ iniciativa legislativa del Gobierno, Centro de Estudios Políticos y Constitucionales, Madrid, 2000, págs. 154 y ss. Como allí se señala, creemos que el texto constitucional no pretende que la distribución del Fondo de Compensación Interterritorial se articule mediante una ley, como tampoco ocurre con ninguna de las otras dos decisiones de las Cortes (sobre tratados internacionales y acuerdos de cooperación entre Comunidades Autónomas) para las que el artículo 74.2 prescribe la resolución de los desacuerdos entre las Cámaras por una Comisión mixta paritaria. De ahí la justificación de que la remisión de proyectos de ley al Senado no aparezca en el artículo 88 de la Constitución. Sin embargo, lo cierto es que la práctica ha llevado a la regulación por ley (probablemente, por ser el instrumento general de materialización de la voluntad del Parlamento, incluso el medio más sencillo y quizás el más lógico) de la fijación periódica de los criterios para la distribución del Fondo de Compensación Interterritorial (regulación por ley prevista en el artículo 16.1 de la Ley Orgánica de Financiación de las Comunidades Autónomas), efectuándose la distribución concreta en las leyes anuales de Presupuestos, con lo que de alguna manera se priva de contenido a la prioridad de tramitación del Senado establecida en el artículo 74.2 en relación con el 158.2. Recogiendo esta práctica, el artículo 22.4 de la Ley del Gobierno se refiere a la remisión de los proyectos de ley "al Congreso de los Diputados o, en su caso, al Senado". La iniciación en el Senado de la tramitación del Proyecto de Ley del Fondo de Compensación Interterritorial (artículo 158.2 en relación con el 74.2 CE) ha tenido ya lugar en cuatro ocasiones (1982, caducado por disolución de las Cámaras; 1983-1984; 1990 y 2001, en este caso, el Proyecto de Ley reguladora de los Fondos de Compensación Interterritorial). 
Sin perjuicio de que se hayan reseñado los preceptos constitucionales que directamente afectan al procedimiento legislativo, no debe olvidarse que, a lo largo del texto constitucional, distintas disposiciones pueden afectar a algunos aspectos del mismo, de manera que habrán de ser tenidas en cuenta en nuestro análisis. Por ejemplo, las limitaciones a la iniciativa contenidas en el artículo 131.2 (reserva al Gobierno de la elaboración de los proyectos de planificación).

Afectan al procedimiento propiamente dicho las disposiciones generales de funcionamiento de las Cámaras contenidas en el capítulo primero del Título III, como las relativas a quórum (artículo 79.1 y 79.2) o a publicidad de las sesiones (artículo 80).

De la regulación constitucional expuesta cabe avanzar algunas conclusiones:

- la falta de exhaustividad y de sistematización de la regulación constitucional del procedimiento legislativo.

- ello afecta en particular al procedimiento legislativo ordinario, absolutamente carente de regulación ${ }^{9}$, salvo en lo que se refiere a la participación del Senado, lo que significa que los Reglamentos de las Cámaras constituirán la fuente normativa básica.

- la previsión constitucional de dos variantes del procedimiento ordinario, como son la delegación legislativa en comisión y la urgencia.

- la previsión, asimismo, de especialidades en el procedimiento de elaboración de determinados tipos de leyes, como las orgánicas y las de Presupuestos Generales del Estado.

- la incidencia que sobre el procedimiento legislativo introduce el sistema autonómico establecido por la Constitución, no sólo por cuanto reserva a los Parlamentos autonómicos la regulación por ley de determinadas materias, sino por prever las especialidades de procedimiento de las leyes orgánicas reguladoras de los Estatutos de Autonomía o de determinadas categorías de leyes relacionadas con las Comunidades Autónomas.

Llegados a este punto, debemos aclarar que no se ha introducido en el examen de la regulación constitucional ninguna referencia a las reglas que rigen la aprobación de los Reglamentos parlamentarios y de las reformas constitucionales, por considerar que no se trata de leyes propiamente dichas. Los primeros son normas con fuerza de ley, pero no son leyes, siendo muchas las diferencias de naturaleza y procedimiento que avalan tal afirmación, que no es el caso de-

9 E. AJA FERNÁNDEZ ("La reforma del procedimiento legislativo en el nuevo Reglamento del Congreso de los Diputados", cit. pág. 89) señala cómo la Constitución introduce múltiples y decisivas innovaciones en la función legislativa, pero lo hace sin variar esencialmente el procedimiento legislativo ordinario. Las innovaciones provienen, bien de las especialidades respecto a este procedimiento ordinario, o bien de las repercusiones que sobre el mismo tiene la aparición de nuevas instituciones. 
tallar aquí. En cuanto a las segundas, tampoco se trata de leyes en sentido estricto, de ahí que, por más que pueda remitirse su tramitación a las reglas que rigen el procedimiento legislativo o regularse como procedimiento especial en algún Reglamento, quedan decididamente fuera del objeto de nuestro estudio.

\section{I.2. Reglamentos de las CÁmaras}

Vista la parquedad normativa de la Constitución en relación con el procedimiento legislativo, su fuente básica de regulación está constituida por los Reglamentos del Congreso de los Diputados y del Senado. No cabe excluir que el Reglamento de las Cortes Generales, previsto en el artículo 72.2 de la Constitución, contenga alguna norma que afecte al procedimiento legislativo (por ejemplo, en relación con la Comisión mixta paritaria prevista en el artículo 74.2 para resolver conflictos entre las Cámaras, que en lo que aquí nos interesa afecta al procedimiento de aprobación del Fondo de Compensación Interterritorial), si no se limita a la regulación de las sesiones conjuntas a que se refiere dicho artículo 72.2. Pero la inexistencia del Reglamento de las Cortes Generales pese a los más de veinticinco años de vigencia de la Constitución lo excluye de nuestra consideración, que queda por tanto reducida a los Reglamentos de las dos Cámaras.

a) El vigente Reglamento del Congreso de los Diputados de 10 de febrero de 1982 (modificado por reformas de 23 de septiembre de 1993, 16 de junio de 1994, 26 de septiembre de 1996, 11 de mayo de 2000, 27 de junio de 2001 y 28 de abril de 2004) dedica su Título V (artículos 108-150) al procedimiento legislativo, dividido en los siguientes capítulos:

- Capítulo primero: De la iniciativa legislativa (artículo 108)

- Capítulo segundo: Del procedimiento legislativo común, a su vez dividido en tres secciones:

- Sección 1. ${ }^{\mathrm{a}}$ De los proyectos de ley (en cinco apartados con numeración romana): artículos 109-123.

- Sección 2. ${ }^{a}$ De las proposiciones de ley: artículos 124-127.

- Sección $3 .{ }^{a}$ De la retirada de proyectos y proposiciones de ley: artículos 128-129.

- Capítulo tercero: De las especialidades en el procedimiento legislativo, integrado por seis secciones:

- Sección $1 .^{a}$ De los proyectos y proposiciones de Ley Orgánica: artículos 130-132.

- Sección 2. ${ }^{a}$ Del Proyecto de Ley de Presupuestos: artículos 133135. 


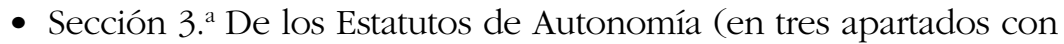
numeración romana): artículos 136-145.

- Sección 4 . $^{a}$ De la revisión y reforma constitucionales: artículos 146-147.

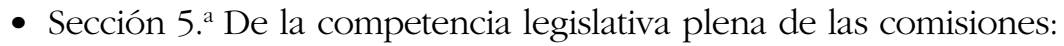
artículos 148-149.

- Sección 6. ${ }^{a}$ De la tramitación de un proyecto de ley en lectura única: artículo 150.

b) Por su parte, el Reglamento del Senado, texto refundido de 3 de mayo de 1994 (modificado en 24 de octubre de 1995, 9 de mayo, 14 de junio y 11 de octubre de 2000, 27 de junio de 2001, 12 de mayo, 3 de noviembre de 2004 y 4 de julio de 2005), dedica su Título Cuarto al Procedimiento legislativo, en tres capítulos:

- Capítulo primero: Del procedimiento legislativo ordinario (dividido en cinco secciones):

- Sección primera. De los textos legislativos remitidos por el Congreso de los Diputados: artículos 104-107.

- Sección segunda. De la iniciativa legislativa del Senado: artículos 108-109.

- Sección tercera. Deliberación en comisión: artículos 110-117.

- Sección cuarta. Deliberación por el Pleno de la Cámara: artículos 118-126.

- Sección quinta. Normas especiales: artículos 127-128.

- Capítulo segundo: De los procedimientos legislativos especiales, dividido en siete secciones:

- Sección primera. De la tramitación de un proyecto de ley en lectura única: artículo 129.

- Sección segunda. De la delegación de la competencia legislativa en las comisiones: artículos 130-132.

- Sección tercera. Del procedimiento de urgencia: artículos 133-136.

- Sección cuarta. De la intervención del Senado en los convenios y acuerdos entre las Comunidades Autónomas y en la distribución del Fondo de Compensación Interterritorial: artículos 137-140.

- Sección quinta. De las leyes de armonización de las disposiciones de las Comunidades Autónomas: artículos 141-142.

- Sección sexta. De los Estatutos de Autonomía: artículo 143.

- Sección séptima. De los Tratados y Convenios Internacionales: artículos 144-147.

- Capítulo tercero: Del procedimiento presupuestario: artículos 148151. 
Con mayor corrección que en el Reglamento del Congreso de los Diputados, el procedimiento de revisión constitucional es aquí objeto del Título Quinto, no constituyendo una especialidad del procedimiento legislativo. Por el contrario, es incorrecta la inclusión de los tratados y convenios internacionales (como también la intervención del Senado en los convenios y acuerdos entre las Comunidades Autónomas, sección cuarta) como procedimiento legislativo especial, siendo más adecuada la opción del Reglamento del Congreso de incluir ambas cuestiones, junto con otras sobre las que carece de competencias el Senado, en un título independiente (el VII), bajo la rúbrica "Del otorgamiento de autorizaciones y otros actos del Congreso con eficacia jurídica directa".

Además de las normas contenidas en estos títulos, habrán de tenerse en cuenta, obviamente, normas incluidas en otros lugares de los Reglamentos, señaladamente: las relativas al funcionamiento de las Cámaras y sus órganos (orden del día, debate, votaciones); la declaración de urgencia en el Reglamento del Congreso (artículos 93 y $94 \mathrm{RC}$ ), el cual no regula un procedimiento legislativo especial de urgencia; y, en el Senado, la intervención de la Comisión General de las Comunidades Autónomas en el procedimiento legislativo, no sólo en la iniciativa (artículo 56.s RS), sino también mediante la emisión de informe (artículo 56.b, j, k, 1, ñ y o; artículo 56 bis 5).

\section{I.3. NORMAS INTERPRETATIVAS Y SUPLETORIAS DE LOS REGLAMENTOS}

Los Reglamentos no son las únicas normas reguladoras del procedimiento legislativo, en la medida en que no abarcan la totalidad de la materia, no sólo por razones de extensión, sino de conveniencia, dada la rigidez de que dotan a la materia que regulan. Como dice Santamaría Pastor ${ }^{10}$, constituyen la norma de cabecera del ordenamiento parlamentario, que puede ser completado con normas de rango inferior, dictadas por los órganos internos de la Cámara.

Estas normas permiten la adecuación del Reglamento a la realidad y pretenden que no se paralice la actividad parlamentaria en un caso concreto por falta de precepto aplicable al supuesto planteado, bien porque al redactarse aquélla no pudieron preverse todas las circunstancias posibles, bien por no ser adecuadas a una situación nueva ${ }^{11}$.

En lo que al procedimiento legislativo se refiere, podemos citar las normas siguientes:

10 J. A. SANTAMARÍA PASTOR, "Comentario al artículo 16", en Comentarios al Estatuto de Autonomía de la Comunidad Autónoma de Navarra, Ministerio para las Administraciones Públicas, Madrid, 1992, pág. 199.

11 He tenido ocasión de ocuparme en otro lugar de la naturaleza y regulación de las normas interpretativas y supletorias de los Reglamentos de las Cámaras: véase P. GARCÍA-ESCUDERO MÁRQUEZ, "Artículo 72.1: Autonomía funcional de las Cámaras: reglamentaria, presupuestaria y de personal", en Comentarios a la Constitución española de 1978, dirigidos por O. Alzaga Villaamil, tomo VI, Cortes Generales, Edersa, Madrid, 1998, págs. 408 y ss., y "Estudio preliminar” a la edición de Reglamentos del Congreso de los Diputados y del Senado, Centro de Estudios Políticos y Constitucionales-BOE, Madrid, 1998, págs. 39 y ss. 
a) En el Congreso de los Diputados:

- Resolución de la Presidencia sobre normas que regulan la calificación de los escritos de enmiendas presentadas a textos legislativos, de 12 de enero de 1983.

- Resolución de la Presidencia de desarrollo del artículo 113 del Reglamento sobre designación y funciones de las ponencias, de 23 de septiembre de 1986.

- Resolución de la Presidencia del Congreso de los Diputados sobre procedimiento a seguir para la tramitación de la reforma de los Estatutos de Autonomía, de 16 de marzo de 1993.

Además existen algunas otras normas relativas a comparecencias, a solicitudes de información o utilización de documentos audiovisuales en las comisiones $^{12}$, o en general a cuestiones de funcionamiento.

\section{b) En el Senado:}

- Norma supletoria para la ordenación del debate, de 14 de febrero de 1984.

- Norma supletoria de la Presidencia del Senado sobre procedimiento a seguir para la tramitación de la reforma de los Estatutos de Autonomía, de 30 de septiembre de 1993.

- Norma interpretativa de la Presidencia del Senado sobre la adopción de acuerdos por las ponencias designadas por las comisiones, de 18 de noviembre de 1997.

Han de añadirse otras normas relativas a solicitudes de documentación o comparecencias por las comisiones, a debate o a votación ${ }^{13}$, y a otros aspectos de funcionamiento.

12 Resolución de la Presidencia sobre trámite previsto en el artículo 203 del Reglamento de la Cámara en materia de comparecencias, de 25 de enero de 1983. Resolución de la Presidencia sobre delegación por las comisiones en sus respectivas Mesas de las facultades a que se refiere el artículo 44 del Reglamento, de 2 de noviembre de 1983. Resolución de la Presidencia del Congreso de los Diputados, de 21 de diciembre de 1998, sobre la utilización de documentos audiovisuales en las comisiones.

13 Norma interpretativa sobre delegación por las comisiones en sus respectivas Mesas de las facultades a que se refieren los artículos 66.1 y 67 del Reglamento del Senado, de 23 de mayo de 1984. Norma interpretativa sobre votación nominal pública por procedimiento electrónico, de 23 de mayo de 1984. Norma interpretativa de la Presidencia del Senado sobre turnos a favor y en contra previstos en los artículos 108.4, 121, 129 y 155.2 del Reglamento del Senado, de 17 de abril de 1985. 


\section{FASES DEL PROCEDIMIENTO LEGISLATIVO}

\section{II.1. SIGNIFICADO}

Como todo procedimiento, el legislativo consiste en una sucesión de trámites ordenados a un fin. Así se suceden las distintas fases del procedimiento legislativo en las Cortes Generales hasta llegar a la aprobación de una ley. Al análisis sintético y unificador del procedimiento legislativo como fenómeno unitario debe seguir, como pone de relieve Galeotti ${ }^{14}$, el momento analítico de la descomposición del dato procedimental ya individualizado y aislado en su unidad, orden no solamente típico de la labor científica que progresa con movimientos alternos de análisis y síntesis, sino seguido por la elaboración doctrinal sobre el procedimiento en general (Carnelutti) y el procedimiento administrativo en particular (Sandulli, Giannini, Gasparri). Las fases (llamadas en otras ocasiones, de forma más metafórica, estadios o etapas, como partes de un camino) significan una fracción temporal, un período interno en el complejo ciclo temporal que comprende el procedimiento legislativo. En este sentido, como pone de relieve García Martínez ${ }^{15}$, todo el procedimiento legislativo, cada una de sus fases, cada requisito, la secuencia temporal de su desarrollo, tienen un significado en sí mismos siempre que se le relacione con el producto final del procedimiento, es decir, con la ley como fuente esencial del Derecho.

El procedimiento legislativo se ha mantenido en lo esencial sin alteraciones durante toda la larga vida del Estado liberal, pese al cambio en la concepción de la ley, lo que Rubio Llorente achaca a la homogeneidad social de la representación parlamentaria ${ }^{16}$. Se configura sobre la base de la discusión, de la que ha de salir, mediante la persuasión, la luz y la verdad, y el Parlamento actúa como órgano cerrado en sí mismo ayudado por formaciones auxiliares (primero secciones, luego comisiones), que analizan las enmiendas presentadas y las defienden ante el Pleno. Evidentemente, este procedimiento arranca del supuesto implícito de que los parlamentarios tienen un criterio propio sobre la propuesta que se les hace, frente a la que, por tanto, están en condiciones de ofrecer alternativas para su debate.

Esta estructuración del procedimiento legislativo, según De Otto ${ }^{17}$, cumple determinadas funciones políticas claves, cuyo esclarecimiento hace compren-

14 S. GALEOTTI, Contributo alla Teoria del procedimento legislativo, Giuffré, Milán, 1957, pág. 223.

15 M. ${ }^{a}$ A. GARCÍA MARTÍNEZ, “La incidencia de la reforma del Reglamento del Congreso en el modelo de procedimiento legislativo", en Estudios de Teoría del Estado y Derecho constitucional en honor de Pablo Lucas Verdú, Universidad Complutense de Madrid-Instituto de Investigaciones Jurídicas, México, 2001, vol. III, págs. 2156-2158.

16 F. RUBIO LLORENTE, «Función legislativa, poder legislativo y garantía del procedimiento legislativo", en El procedimiento legislativo. VJornadas de Derecho Parlamentario, Congreso de los Diputados, Madrid, 1997, pág. 27.

17 I. DE OTTO, "La función política de la legislación", en Parlamento y sociedad civil (Simposium), Universidad de Barcelona, Barcelona, 1980, págs. 49 y ss. 
sible el mantenimiento de las esclerotizadas estructuras parlamentarias. Para De Otto, la característica básica del procedimiento legislativo en cuanto proceso de creación de normas es la de ser un procedimiento de decisión no programado, en el que el Derecho es tratado como una variable y no como una estructura dada $^{18}$, de forma que, aun sin haber sido objeto de reforma, cumple su función legitimadora de las decisiones.

\section{II.2. Delimitación Y FaSES}

Delimitamos el procedimiento legislativo excluyendo de nuestro examen, sin entrar en disquisiciones teóricas o polémicas doctrinales, las llamadas fases de iniciativa e integrativa de eficacia, situadas fuera del ámbito parlamentario y atribuidas a entidades (con la excepción de las proposiciones de ley de iniciativa parlamentaria), asimismo ajenas al Parlamento.

Centrados, pues, en la llamada fase constitutiva del procedimiento legislativo o procedimiento legislativo en sentido estricto, es decir, el procedimiento parlamentario, podemos decir que se compone de una secuencia de distintos momentos de deliberación por distintos órganos sobre el texto fruto de la iniciativa, que se irá modificando a lo largo de estas fases a través de la votación de las enmiendas propuestas por los parlamentarios y los grupos, hasta llegar a una decisión final sobre el texto de la futura ley. Siguiendo la visión del procedimiento legislativo como transposición del proceso judicial que aporta Kriele ${ }^{19}$, a la propuesta de norma o hipótesis normativa se le formulan hipótesis alternativas (enmiendas) a partir de las cuales se desarrolla el debate y discusión para concluir en la adopción de una decisión racional (ley).

Estas consideraciones nos permiten abordar un esquema de las fases del procedimiento legislativo de las Cortes Generales, con la advertencia previa de que vamos a referirnos al procedimiento común u ordinario, de forma que una $\mathrm{O}$ varias de estas fases pueden verse afectadas $-\mathrm{O}$ incluso eliminadas - como consecuencia de las especialidades de procedimiento que señalaremos en el apartado siguiente. La secuencia básica respondería a tres momentos, correspondientes a la presentación de enmiendas, el debate en comisión y el debate en el Pleno, a su vez reproducidos en las dos Cámaras. Con un mayor detalle, podemos señalar las fases que se enumeran a continuación.

\section{a) Congreso de los Diputados}

El esquema de tramitación de los textos legislativos en el Congreso de los Diputados responde a una división en plazo de enmiendas, comisión (con la doble intervención de la ponencia y la Comisión) y Pleno, aunque en esta di-

18 Ibidem, pág. 52.

19 M. KRIELE, Introducción a la Teoría del Estado, Depalma, Buenos Aires, 1980, págs. 142 y ss. 
visión se inserta, con anterioridad a que comience a actuar la Comisión correspondiente, el debate de totalidad ante el Pleno cuando se presentan enmiendas de esta naturaleza.

1. ${ }^{\circ}$ Admisión a trámite de la iniciativa legislativa. Decisión que corresponde a la Mesa de la Cámara, quien verifica el cumplimiento de los requisitos de cada tipo de iniciativa y, en su caso, ordena su publicación, la apertura del plazo de presentación de enmiendas y el envío a la Comisión competente para la tramitación (primer texto publicado de la iniciativa).

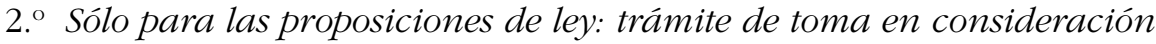
por el Pleno. Si no se supera este trámite, termina aquí la tramitación de las proposiciones. Las proposiciones de ley tomadas en consideración por el Senado no se someten a la toma en consideración por el Congreso, pero sí cabe la posibilidad de que sean objeto de enmiendas de totalidad de devolución (126.5 RC).

3. Plazo de presentación de enmiendas por los diputados y los grupos parlamentarios. Pueden ser enmiendas a la totalidad (de devolución o de texto alternativo), que sólo pueden presentar los grupos, o al articulado. No caben enmiendas a la totalidad de devolución de las proposiciones de ley tomadas en consideración, salvo (criterio tal vez discutible) para las que tienen su origen en la Segunda Cámara ${ }^{20}$.

4. ${ }^{\circ}$ Debate de totalidad de los proyectos de ley en el Pleno, en caso de haberse presentado enmiendas a la totalidad. De aprobarse una enmienda de devolución, termina aquí la tramitación del proyecto de ley, que es devuelto al Gobierno. Si se aprueba una enmienda a la totalidad de texto alternativo, se abre un nuevo plazo de enmiendas sólo al articulado.

Si las enmiendas a la totalidad son rechazadas, continúa el procedimiento con la fase de comisión, compuesta por dos momentos o subfases:

5. Informe de la ponencia constituida en el seno de la Comisión sobre las enmiendas presentadas al texto legislativo, proponiendo su aceptación o su rechazo, al que acompaña como anexo el texto resultante de la incorporación de las enmiendas aceptadas (segundo texto publicado).

20 A diferencia de las restantes proposiciones de ley, tomadas todas ellas en consideración por el Congreso, cabe presentar enmiendas a la totalidad de devolución al Senado (art. 126.5 RC). Cabría pensar que este precepto viola la facultad de iniciativa del Senado, proclamada por el artículo 87.1 de la Constitución, subordinándola a la voluntad del Congreso, aunque lo que se hace en realidad es dar a las proposiciones de ley tomadas en consideración por dicha Cámara el mismo tratamiento que a los proyectos del Gobierno, sometidos en el debate y votación de totalidad a la posibilidad de aprobación tanto de enmiendas a la totalidad de devolución como de texto alternativo y, en este sentido, tal vez quepa aceptar lo que en un principio parece contrario a la Constitución, como decisión del Congreso, al comienzo de la tramitación, sobre la viabilidad de la iniciativa procedente de un sujeto ajeno. 
6. Debate en la Comisión, sobre la base del informe de la Ponencia y de las enmiendas presentadas, del que resulta la aprobación de un dictamen que se eleva al Pleno (tercer texto publicado, con las enmiendas aceptadas incorporadas).

En el plazo de cuarenta y ocho horas, los grupos parlamentarios han de presentar la relación de votos particulares y enmiendas no aceptadas por la Comisión que pretenden defender ante el Pleno de la Cámara.

7. Deliberación en el Pleno, en el que se defienden y votan los votos particulares presentados y el dictamen de la Comisión. El texto aprobado (cuarto texto publicado) será remitido al Senado, de conformidad con el artículo 90.2 de la Constitución.

b) Senado

La estructuración en fases del debate por la Segunda Cámara tiene como condicionante la brevedad de plazos impuesta por la Constitución, causa de la acumulación de los debates de totalidad (o sobre las propuestas de veto presentadas) y sobre el articulado en la deliberación final por el Pleno.

1. Admisión a trámite, publicación y apertura del plazo de enmiendas, además de su envío a la Comisión competente (quinto texto publicado, idéntico al aprobado por el Congreso de los Diputados).

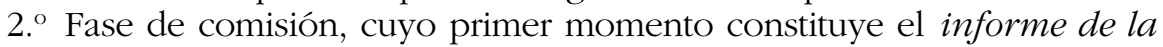
ponencia sobre el proyecto y sobre las enmiendas presentadas (sexto texto publicado).

3. Debate en la Comisión, del que resulta el dictamen (séptimo texto publicado). Este debate, y la consiguiente votación, se inicia con la discusión de las propuestas de veto.

El plazo para la presentación de votos particulares para su defensa en Pleno termina al día siguiente del dictamen.

4. ${ }^{\circ}$ Deliberación por el Pleno, que comienza con el debate y votación sobre las propuestas de veto o, si no las hubiere, con turnos sobre la totalidad del proyecto o proposición. De aprobarse alguna propuesta de veto, concluye el procedimiento en el Senado.

En otro caso, se continúa con el debate sobre el articulado, defendiendo y votando los votos particulares y el texto del dictamen de la Comisión, del que resulta el texto aprobado por el Pleno (octavo texto publicado).

En este punto concluye el procedimiento legislativo, cuando el texto del proyecto o proposición remitido por el Congreso de los Diputados no ha sido objeto de modificaciones por la Alta Cámara. De haberse aprobado un veto o enmiendas al mismo, serán remitidos al Congreso de los Diputados acompañados de mensaje motivado (noveno texto publicado), de conformidad con el artículo 90.2 de la Constitución, para su tramitación en una última fase que tendrá lugar en esta Cámara. 
c) Congreso de los Diputados

1. Debate final en el Pleno del Congreso, sobre el veto o sobre las enmiendas presentadas. El primero ha de ser rechazado por mayoría absoluta en una primera votación de ratificación del texto inicialmente aprobado por el Congreso. Las segundas son aceptadas o rechazadas por mayoría simple (décimo texto publicado).

2. ${ }^{\circ}$ En su caso, transcurridos dos meses, segunda votación del texto inicial para levantar el veto del Senado, esta vez por mayoría simple. Si no se alcanza, el proyecto queda rechazado. 


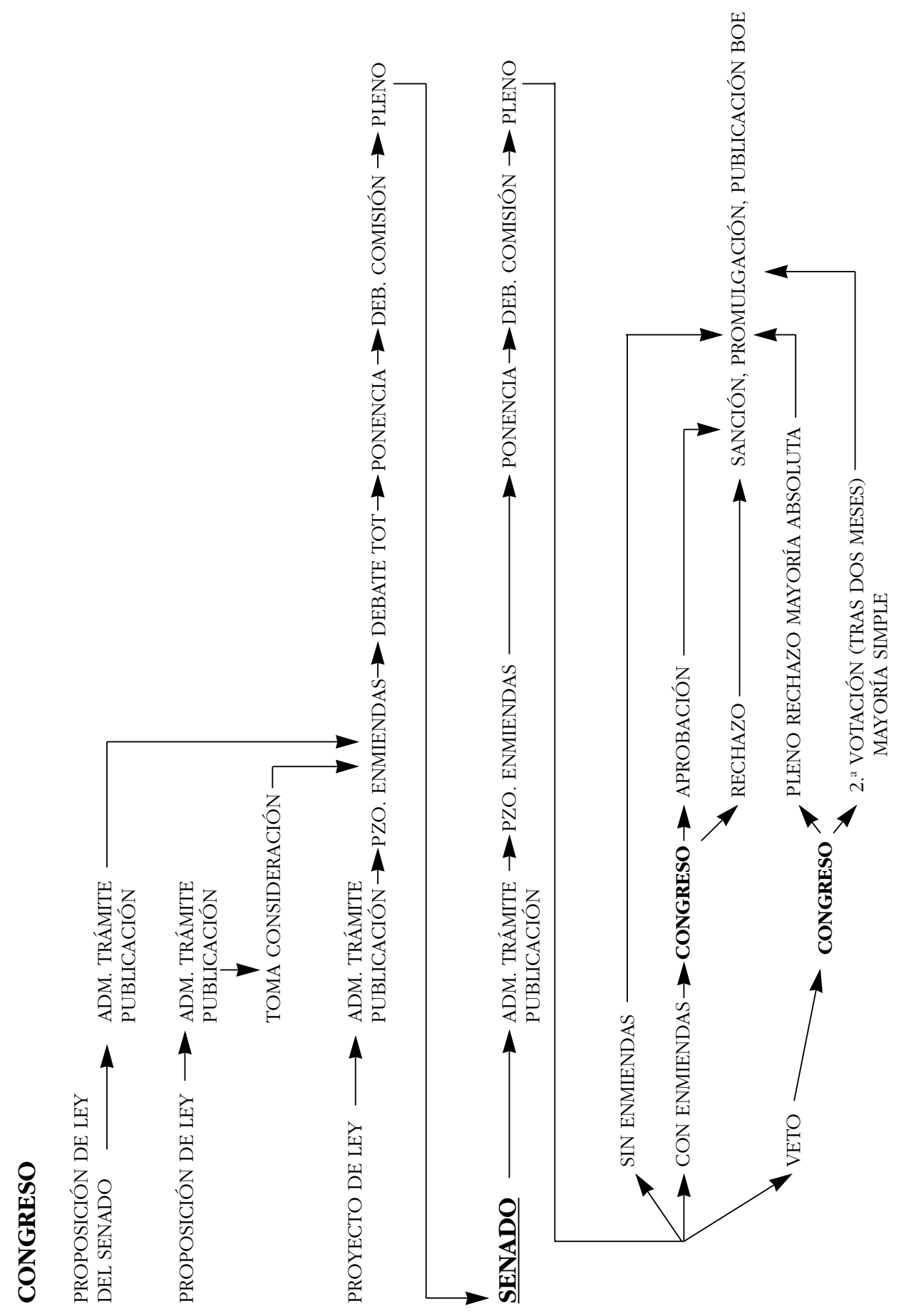




\section{TIPOS DE PROCEDIMIENTOS LEGISLATIVOS}

\section{III.1. EvoluCiÓN}

El procedimiento legislativo en la historia constitucional española era único, en perfecta correlación con el único concepto de ley, con apenas alguna referencia en las Constituciones históricas a la anualidad de las leyes presupuestarias o a la prevalencia del Congreso sobre el Senado en las leyes sobre "contribuciones y créditos", consecuencia de la distinción entre función legislativa y presupuestaria.

Los propios Reglamentos de las Cámaras, como recuerda Ruiz Robledo $^{21}$, apenas contenían un par de especialidades de tramitación para los códigos, cuyos proyectos podían dar lugar a varias discusiones generales por libros o títulos (a partir del Reglamento del Congreso de 1937) y cuya tramitación no decaía automáticamente al final de la legislatura, permitiéndose que las nuevas Cortes pudieran reanudar la discusión en el mismo punto (Reglamento del Congreso de 1847). De modo que, en los Reglamentos históricos, se produce una regulación única y menos extensa que en las actuales, incluida la más completa de las secciones séptima y octava del Reglamento de 29 de noviembre de 1934, en que se distinguía diversidad de leyes y de iter legis: Estatutos de Autonomía con iniciativa especial, leyes de bases, con mayoría cualificada, etc.

No será hasta el Reglamento de las Cortes Españolas de 1971 cuando se distinga entre el procedimiento legislativo ordinario y los especiales, incluidos algunos que no eran tales, como los conflictos de competencia con el Gobierno y la aprobación por ley de la ratificación de los tratados que afectan a la plena soberanía o a la integridad territorial. Los otros dos serán el germen de las especialidades actuales: el procedimiento presupuestario y el procedimiento en comisión.

Los Reglamentos provisionales de 1977 distinguen entre el procedimiento legislativo denominado ordinario por el Reglamento del Congreso, y lo que el Reglamento del Senado califica de procedimientos legislativos especiales.

El Reglamento provisional del Congreso regula en el Título VI, dedicado al procedimiento legislativo, además del ordinario, otros que no califica: el procedimiento de urgencia, el presupuestario, los tratados y convenios internacionales y la elaboración de la Constitución.

El Reglamento provisional del Senado considera procedimientos legislativos especiales los tres primeros, siendo objeto de un título independiente el procedimiento para la discusión del proyecto de Constitución.

21 A. RUIZ ROBLEDO, "Sobre los tipos de procedimientos legislativos", en El procedimiento legislativo. V Jornadas de Derecho Parlamentario, Congreso de los Diputados, Madrid, 1997, pág. 654 . 


\section{III.2. Regulación VIGENTE}

La regulación normativa vigente del procedimiento legislativo en ambas Cámaras incluye en el Título relativo al procedimiento legislativo (quinto en el RC, cuarto en el RS), una distinción entre el procedimiento legislativo denominado común por el RC y ordinario por el $\mathrm{RS}^{22}$, de una parte, y los llamados procedimientos legislativos especiales por el RS y, más matizadamente, especialidades en el procedimiento legislativo por el $\mathrm{RC}^{23}$.

Estas serán, para el Reglamento del Congreso, reguladas en secciones independientes, las relativas a:

1. los proyectos y proposiciones de ley orgánica.

2. el proyecto de ley de Presupuestos.

3. los Estatutos de Autonomía (a su vez subdividida en el procedimiento ordinario, el previsto en el artículo 151 de la Constitución y la reforma de los Estatutos).

4. la revisión y reforma constitucionales.

5. la competencia legislativa plena de las comisiones.

6. la tramitación de un proyecto de ley en lectura única.

La urgencia no constituye para el Reglamento del Congreso una especialidad exclusiva del procedimiento legislativo, sino un procedimiento que puede aplicarse a cualquier asunto, de ahí su regulación en el Capítulo sexto (De la declaración de urgencia, artículos 93 y 94) del Título IV, relativo a las Disposiciones generales de funcionamiento.

22 Para L. VILLACORTA MANCEBO (Hacia el equilibrio de poderes: comisiones legislativas y robustecimiento de las Cortes, Universidad de Valladolid, Valladolid, 1989, pág. 319), la ausencia de uniformidad en la denominación de este procedimiento por los Reglamentos del Congreso y del Senado está plenamente justificado, en la medida en que mal se puede denominar ordinario al del Congreso, después del sistema de delegación general a favor de las comisiones establecido por el artículo 148.1 RC. De haberlo hecho, dice el autor, podríamos encontrarnos ante la paradójica situación que se produce en el ordenamiento italiano, donde el artículo 72.1 utiliza la expresión procedimiento normal para aquél en que la aprobación corresponde al Pleno, cuando se utiliza para una cuarta parte de las tramitaciones en virtud de la delegación a favor de las comisiones autorizada por el artículo 72.3. F. SANTAOLALLA LÓPEZ (Derecho parlamentario español, Editora Nacional, Madrid, 1984, pág. 237) califica de preferente al procedimiento legislativo especial de competencia legislativa plena de las comisiones, "hasta el punto de que puede decirse que constituye un procedimiento tan común" como el así denominado por el Reglamento. Véase más adelante, en este mismo apartado, nuestra visión del procedimiento descentralizado como una variante del ordinario.

23 Curiosamente, los Reglamentos utilizan criterios diversos a la hora de ordenar los procedimientos especiales. El Reglamento del Congreso comienza su regulación por los que podemos llamar de momento especiales por razón de la materia, para concluir con los abreviados, mientras que el Reglamento del Senado sitúa en primer lugar los que suponen una abreviación del procedimiento (lectura única, delegación en comisión y urgencia), continuando con los procedimientos especiales en función de las normas que han de tramitarse. Este es el criterio adoptado, en la VIII legislatura, en el Borrador de Reforma del Reglamento del Congreso de los Diputados presentado por el Presidente del Congreso a los grupos parlamentarios, según figura en la página web de la Cámara. 
Para el Reglamento del Senado, constituyen procedimientos legislativos especiales, regulados en secciones distintas, los relativos a:

1. la tramitación de un proyecto de ley en lectura única

2. la delegación de la competencia legislativa en las comisiones

3. el procedimiento de urgencia

4. la intervención del Senado en los convenios y acuerdos entre las Comunidades Autónomas y en la distribución del Fondo de Compensación interterritorial

5. las leyes de armonización de disposiciones de las Comunidades Autónomas

6. los Estatutos de Autonomía

7. los tratados y convenios internacionales

El procedimiento presupuestario es objeto de regulación en el título relativo al procedimiento legislativo, pero en un capítulo independiente del ordinario y de los especiales.

Asimismo, el procedimiento de revisión constitucional es objeto de un título independiente en el Reglamento del Senado.

La doctrina ha criticado esta pluralidad de procedimientos. Así, Pendás García declara que no existe siquiera, en rigor, un procedimiento-tipo que sirva de modelo a los restantes o que permita de verdad una eficaz aplicación supletoria de sus reglas ${ }^{24}$ (afirmación, a mi modo de ver, excesiva) ni es posible asegurar de cuántas lecturas está compuesto el procedimiento legislativo en las Cortes Generales ${ }^{25}$, lo que es rigurosamente cierto en la medida en que existe una pluralidad de modelos que impide hablar de un modelo único en el sentido de indentificación del número de lecturas que recibe un texto legislativo en la Cámara. El sistema actual de Derecho español es de dos lecturas, tanto si se considera, como lo hace García Martínez, primera lectura a la mera publicación del texto (así ocurre actualmente en el Parlamento británico, cuyo sistema sigue siendo calificado de tres lecturas), como si se aplica el concepto de lectura al examen del texto tanto por el Pleno como por la Comisión. Los Reglamentos vigentes avalan esta interpretación, al incluir un procedimiento especial denominado "de lectura única", referido al exclusivo examen por el Pleno.

De acuerdo con la pluralidad de procedimientos señalada, el sistema español de dos lecturas presenta dos excepciones:

24 B. PENDÁS GARCÍA, "Procedimiento legislativo y calidad de las leyes”, Revista española de Derecho Constitucional, n. ${ }^{\circ} 28,1990$, pág. 83.

25 M. FRAILE, por su parte, coincide en que el procedimiento español carece de una estructura que se dé necesariamente, pudiendo ir desde una a tres lecturas e, incluso en el caso de que sea una sola, ésta no necesariamente tiene lugar ante el Pleno ("Prólogo" a M. ${ }^{a}$ A. GARCÍA MARTÍNEZ, El procedimiento legislativo, Congreso de los Diputados, Madrid, 1987, pág. 12). 
- se dan tres lecturas en el Congreso de los Diputados en el supuesto de presentación de enmiendas a la totalidad del proyecto o proposición de ley, en cuyo caso habrá un primer debate en Pleno sobre dicha totalidad (art. $112 \mathrm{RC}$ ).

- una sola lectura tendrá lugar en el ya citado procedimiento de lectura única previsto por los Reglamentos (art. 150 RC y 129 RS) y también en el procedimiento descentralizado en comisión (asimismo previsto como procedimiento especial en ambos Reglamentos) cuando no haya debate previo de totalidad en el Congreso. La cuestionable amplitud de la regulación contenida en el artículo 148 del Reglamento del Congreso, por la presunción de delegación del Pleno para todos los proyectos constitucionalmente delegables, ha convertido a este procedimiento en el auténtico procedimiento ordinario. Sobre este punto volveremos más adelante.

\section{III.3. INTENTO DE CLASIFICACIÓN}

a) Delimitación de los procedimientos legislativos existentes

La primera tarea que debemos abordar para un intento de clasificación de los procedimientos legislativos en nuestro ordenamiento parlamentario, consiste en delimitar aquellos procedimientos que deben estar incluidos en aquélla, y excluir los que no deben estar, pese a la regulación reglamentaria.

- La primera exclusión que realizaremos será la relativa a la reforma constitucional, por razón de su objeto. Sabemos que la Constitución es la ley de leyes o la norma normarum, pero su especial naturaleza nos inclina a creer que es correcta la regulación de su reforma fuera del procedimiento legislativo, como hace el Reglamento del Senado, con base por otra parte en la propia Constitución, la cual, siguiendo las reglas de técnica normativa, dedica su último título a la reforma. Aunque la regulación que los Reglamentos contengan haya de remitirse por fuerza al procedimiento legislativo, estableciendo las especialidades necesariamente derivadas de la regulación contenida en los artículos 166 a 169 de la Constitución, ello no obsta a que no se trate de un procedimiento legislativo especial, sino del procedimiento de tramitación de una reforma constitucional, norma diferente a la ley.

- La segunda exclusión se refiere al procedimiento para la autorización de ratificación de tratados y convenios internacionales, correctamente incluida en el Reglamento del Congreso en otro título, bajo la rúbrica "Del otorgamiento de autorizaciones y otros actos del Congreso con eficacia directa". Cuando estos tratados o acuerdos caen bajo el ámbito del artículo 193 de la Constitución, su autorización ha de realizarse mediante ley orgánica, tramitada mediante el procedimiento corres- 
pondiente a este tipo de leyes. En otro caso, la autorización que han de prestar las Cortes Generales no constituye en modo alguno un acto legislativo, sino un acto de indirizzo político de naturaleza muy diferente (autorización singular de una actuación del Gobierno), que se refleja en su contenido. Otra cosa es que, dado que el procedimiento ordinario de tramitación de un texto por las Cámaras sea el legislativo, por economía normativa pueda haber una remisión a dicho procedimiento, con la adecuación de los trámites a la distinta finalidad a que va orientado el procedimiento de autorización y a las especificidades del texto a tramitar (que, por ejemplo, se reflejan en la imposibilidad de modificar el texto del acuerdo o convenio ya firmado, aunque no ratificado, por los Estados contratantes).

- La tercera exclusión se refiere a la intervención en los convenios y acuerdos entre Comunidades Autónomas, que el Reglamento del Senado regula entre los procedimientos legislativos especiales, junto a la distribución del Fondo de Compensación Interterritorial. Así como esta distribución se realiza mediante ley (aunque no parezca que tal fuera la intención del constituyente $\left.{ }^{26}\right)$, siendo por tanto correcta su tramitación mediante un procedimiento especial, respecto de los convenios y acuerdos de las Comunidades Autónomas la actuación de las Cortes Generales consiste, bien en la recepción de una comunicación, bien en la autorización de su conclusión. Esta naturaleza de autorización de la intervención de las Cámaras, que no es sino un acto de control de una actuación de las Comunidades Autónomas, muestra, en forma similar a como se ha expuesto respecto de la autorización de tratados y convenios internacionales, que no nos hallamos en modo alguno ante un procedimiento legislativo especial, por más que también aquí su tramitación se remita a dicho procedimiento. Es correcta, pues, la opción del Reglamento del Congreso de incluir los actos del Congreso en relación con las Comunidades Autónomas, al igual que los tratados internacionales, en el título relativo al otorgamiento de autorizaciones $y$ otros actos del Congreso con eficacia jurídica directa.

b) Características que permiten una agrupación de los procedimientos legislativos existentes.

Hemos podido ver que, a pesar de que la clasificación básica a realizar entre los procedimientos legislativos sería sumamente sencilla, distinguiendo entre ordinario o común y especiales, el Reglamento provisional del Congreso evitaba esta segunda rúbrica y el de 1982 la matiza aludiendo a las especialidades del procedimiento legislativo.

Avanzando un poco más, en la enumeración de procedimientos que hemos mantenido para nuestra clasificación se aprecian diferencias considerables entre la singularidad de unos y otros procedimientos calificados de especiales.

26 Véase nota 8. 
García Martínez ${ }^{27}$ puso, a nuestro juicio, el dedo en la llaga al distinguir dos series de motivos sobre los que puede basarse la singularidad de tramitación: por razón de la materia (en los que la naturaleza de la norma es la que determina el procedimiento a utilizar, que normalmente supone una agravación de alguno de los trámites básicos del procedimiento legislativo ordinario) y por razón del tiempo de tramitación, que supone normalmente un acortamiento de la secuencia temporal total del procedimiento. En sentido similar, Espín ${ }^{28}$ distingue entre procedimientos especiales constitucionalmente asociados a un determinado tipo de ley y procedimientos de carácter genérico, y De Esteban y González Trevijano ${ }^{29}$ entre procedimientos asociados a determinadas clases de normas jurídicas y procedimientos legislativos de carácter genérico no asociados a ningún tipo de norma jurídica en particular. Sobre esta base, Ruiz Robledo $^{30}$ propone una división tripartita de los procedimientos legislativos en ordinario, abreviados y especiales. Los abreviados no se cualifican por su objeto material y el órgano legitimado para decidir puede elegir libremente, una vez comprobada la existencia de unos requisitos, entre el ordinario o el abreviado, mientras que los especiales serían de empleo forzoso para una determinada materia que tiene un régimen constitucional determinado, siendo por tanto especiales los procedimientos que se emplean para elaborar leyes que poseen un régimen diferente al de la ley ordinaria ${ }^{31}$.

\section{c) Clasificación adoptada}

De un criterio similar vamos a partir para la clasificación que se propone. En ella distinguimos los procedimientos especiales por razón de la materia sobre la que recaen (incluyendo, como hace el Reglamento del Congreso de los Diputados, el procedimiento presupuestario, pues aun siendo ejercicio de una función de las Cortes Generales distinta de la legislativa, los Presupuestos Generales del Estado se tramitan como proyecto de ley, con especialidades procedimentales) de las que podemos llamar variantes o especialidades en el procedimiento que tienden a abreviar el mismo y que pueden darse tanto en el procedimiento ordinario como en los especiales, actuando por tanto de forma transversal a los distintos procedimientos. Un lugar aparte merece, no obstante,

27 M. ${ }^{a}$ A. GARCÍA MARTÍNEZ, El procedimiento legislativo, cit., pág. 276.

28 E. ESPÍN, en L. LÓPEZ-GUERRA y otros, Derecho Constitucional II, 5. ${ }^{a}$ ed.,Tirant lo Blanch, Valencia, 2002, págs. 112-113.

29 J. DE ESTEBAN y P. GONZÁLEZ TREVIJANO, Curso de Derecho Constitucional español, III, Facultad de Derecho, Universidad Complutense, Madrid, 1994, pág. 561.

30 A. RUIZ ROBLEDO, "Sobre los tipos de procedimientos legislativos", cit., pág. 657.

31 Ibidem, pág. 661. RUIZ ROBLEDO concluye en que, en la medida en que los tipos de ley sólo pueden ser fijados por la Constitución, los Reglamentos deben limitarse a los mandatos constitucionales o estatutarios, no creando ex novo un procedimiento especial. Es éste el único punto de su exposición con el que no concuerdo totalmente. Determinadas leyes, digamos, especiales en cuanto a su contenido, no en cuanto a su naturaleza de ley ordinaria, pueden tener establecidas por ley (y por tanto también reformables o derogables por ley) características que influyan en su procedimiento de tramitación. 
el procedimiento descentralizado en comisión, porque no se cumplen en él las características de las variantes del procedimiento llamadas abreviadas, ya que las bases de su regulación se encuentran en la Constitución y no puede operar respecto de todo tipo de leyes.

Según esto, distinguiremos una pluralidad de procedimientos:

1. Procedimiento legislativo común u ordinario, cuyas fases se han delineado en el apartado anterior, regulado en los artículos 108 a 127 RC y 104 a 128 RS.

2. Procedimiento descentralizado en comisión. Como se ha señalado, este procedimiento (llamado también de delegación de competencia legislativa plena en las comisiones) no puede ser calificado de procedimiento especial conforme a los parámetros adoptados, pues sus bases normativas se encuentran en la Constitución y no se aplica a un determinado tipo de normas. Tampoco cabe, como en los llamados procedimientos abreviados, su aplicación a todos los procedimientos, antes bien, queda excluido de los procedimientos especiales más característicos, como son los relativos a la tramitación de las leyes orgánicas (y por tanto también, de los Estatutos de Autonomía) y de la Ley de Presupuestos Generales del Estado.

Esto nos lleva a considerar al procedimiento descentralizado en comisión como una variante del procedimiento ordinario (y así lo reflejaremos en el cuadro final), el cual podría subdividirse en dos subtipos, procedimiento en Pleno o delegado en comisión.

Su regulación está contenida en el artículo 75.2 y 3 de la Constitución y, como especialidad en el procedimiento legislativo o como procedimiento legislativo especial, en los artículos 148 y 149 RC, y 130 a 132 RS.

Un argumento más nos induce a presentar el procedimiento descentralizado en comisiones, o de delegación de competencia legislativa en las mismas, como una variante del procedimiento ordinario. Como se ha señalado, el artículo 148 RC presume el acuerdo de delegación del Pleno para todos los proyectos constitucionalmente delegables, presunción de dudosa constitucionalidad (el voto de diputados y senadores, conforme al artículo $79.3 \mathrm{CE}$, es personal e indelegable $)^{32}$ que ha

32 En el mismo sentido, M. ${ }^{a}$ A. GARCÍA MARTÍNEZ (El procedimiento legislativo, cit., pág. 295), E. RECODER DE CASSO ("Comentario al artículo 75.2", en Comentarios a la Constitución, dirigidos por F. Garrido Falla, 2. ${ }^{\text {a }}$ ed., Madrid, 1985, pág. 1168), F. SANTAOLALLA LÓPEZ (Derecho parlamentario español, cit., pág. 238) y R. PUNSET ("La fase central del procedimiento legislativo, Revista española de Derecho Constitucional, n. ${ }^{\circ} 14,1985$, cit., pág. 130). Aun reconociendo que la regulación contenida en el art. $148.1 \mathrm{RC}$ no es la más respetuosa con el texto del artículo 75.2 CE, A. RUIZ ROBLEDO ("La delegación legislativa en las comisiones", en Las comisiones parlamentarias, Parlamento Vasco, Vitoria-Gasteiz, 1994, pág. 474) considera exagerada la importancia que se ha dado a tal inadecuación, dado que la presunción que se establece es iuris tantum, y porque no hay 
convertido al procedimiento descentralizado en el ordinario, en la medida en que para la aprobación por el Pleno de leyes sobre materias no excluidas de delegación por el artículo 75.3 de la Constitución, es preciso un acuerdo expreso del Pleno, a propuesta de la Mesa, oída la Junta de Portavoces ${ }^{33}$.

3. Procedimientos especiales para la tramitación de determinados tipos de leyes $^{34}$

\subsection{En los Reglamentos de ambas Cámaras:}

- Proyecto de Ley de Presupuestos Generales del Estado (artículo 134 CE, artículos 133-136 RC, 148-150 RS) ${ }^{35}$.

- Aprobación y reforma de los Estatutos de Autonomía, que comprenden a su vez varios procedimientos, en función de las especialidades establecidas por la Constitución (Estatutos correspondientes a Comunidades Autónomas que han accedido a la autonomía por la vía del artículo 143 o del artículo 151) o, en cuanto a su reforma, por los propios Estatutos (que dieron lugar a Resoluciones de la Presidencia del Congreso de los Diputados de 23 de enero de 1991 y de 16 de marzo de 1993 y a Normas supletorias de la Presidencia del Senado de 15 de febrero de 1991 y de 30 de septiembre de 1993).

- Proyectos de ley de armonización de disposiciones de las Comunidades Autónomas, cuya tramitación, sobre la base del art. 150.3 CE, es

posibilidad de que la voluntad de la Comisión no coincida con la del Pleno (argumento este último no jurídico, criticamos nosotros). En el mismo sentido, L. VILLACORTA MANCEBO (Hacia el equilibrio de poderes: comisiones legislativas y robustecimiento de las Cortes, cit., págs. 415 y ss. y 486) no comparte la tendencia doctrinal que duda acerca de la constitucionalidad de la delegación general recogida en el artículo $148.1 \mathrm{RC}$, por cuanto la votación expresa del Pleno está garantizada por la votación efectuada en el momento de la aprobación del Reglamento, que puede ser derogado para situaciones individuales por medio de votaciones concretas.

33 Puede verse sobre el procedimiento descentralizado, además de la obra citada en la nota anterior, D. BASTERRA MONSERRAT, Las comisiones legislativas con delegación plena, Comares, Granada, 1997.

34 Como señala E. AJA FERNÁNDEZ ("Caracteres y principios generales del procedimiento legislativo", Anuari de Dret Politic, 1983, pág. 160), la construcción de los distintos tipos de ley se realiza en parte sobre una mayoría cualificada o un procedimiento agravado; ambos reflejan un consenso político superior al normal, bien porque la materia se juzgue especialmente importante $-\mathrm{y}$ aquí sí reaparece un elemento material en la definición del tipo especial de ley-, bien porque se considere la intervención de las Cortes potencialmente peligrosa para la distribución ordinaria de competencias entre el Estado y las Comunidades Autónomas.

35 El Reglamento del Congreso, en la medida en que se refiere al procedimiento legislativo especial para el proyecto de Ley de Presupuestos, sitúa en otro lugar, en el procedimiento legislativo común, el régimen de las enmiendas (art. 111) o de las proposiciones del ley (art. 126.2) que impliquen aumento de créditos o disminución de ingresos. Por el contrario, el Reglamento del Senado incluye el régimen de estas enmiendas y proposiciones de ley (art. 151) en un tercer capítulo del Título dedicado al procedimiento legislativo, relativo al procedimiento presupuestario, separado del ordinario y de los especiales. 
regulada como procedimiento especial en el RS (artículos 141 y 142) y en el RC junto con los actos del Congreso en relación con las Comunidades Autónomas (art. 168). Esto podría ser correcto si sólo se regulara la concesión de la autorización al Gobierno, pero curiosamente es el Reglamento del Congreso y no el del Senado (que lo regula como procedimiento especial), el único que contempla una especialidad plenamente coherente en la tramitación del proyecto de ley posterior, en concreto en relación con las enmiendas (artículo 168.3 RC).

\subsection{En el Reglamento del Congreso de los Diputados:}

- Proyectos y proposiciones de ley orgánica, cuya especialidad afecta sólo a la tramitación en el Congreso de los diputados, conforme al artículo 81 de la Constitución. Regulado por tanto en los arts. 130 a 132 RC, aunque algunas dudas se hayan planteado en el Senado, por ejemplo, en relación con el desglose de materias orgánicas o con la introducción de enmiendas de carácter orgánico en esta Cámara.

\subsection{En el Reglamento del Senado:}

- Proyecto de Ley del Fondo de Compensación Interterritorial (artículo 140 RS), no contemplado, pese a las especialidades introducidas por el artículo 74.2 de la Constitución, en el Reglamento del Congreso ni como procedimiento legislativo ni como forma de adopción de la decisión a que se refiere el texto constitucional.

\section{Procedimientos legislativos abreviados}

4.1. Caracteres. Es común a estos procedimientos su finalidad de obtener un acortamiento en la tramitación de los proyectos de ley, bien mediante una reducción de los plazos (urgencia), bien mediante una eliminación de trámites (lectura única y el propio procedimiento descentralizado en comisión, que por sus especiales características hemos optado por calificar de variante del procedimiento ordinario).

Asimismo, comparten como característica la posibilidad de opción por este procedimiento que se presenta al órgano legitimado para decidir $^{36}$, si se cumplen los requisitos señalados por el Reglamento

36 La variedad de procedimientos y la variedad de opciones dentro de los mismos, señala I. ASTARLOA HUARTE-MENDICOA ("Perspectivas de modificación del procedimiento legislativo", cit., pag. 406), proporcionan una importante flexibilidad a las Cámaras a la hora de decidir los trámites a seguir para cada iniciativa legislativa, de forma que cabe hablar de una regulación del procedimiento legislativo bajo el principio dispositivo, que deja a los aplicadores del procedimiento un margen importante de elección sobre los trámites a seguir. ASTARLOA cree que ello permite responder con agilidad a las necesidades, aunque repercuta en la imprevisibilidad de los trámites 
(en cuanto a la solicitud, simplicidad...) y su posible combinación con otros procedimientos, ordinarios o especiales. En este sentido hablamos de aplicación transversal a los distintos procedimientos (aunque puede haber alguna excepción, en particular respecto del de lectura única).

4.2. Enumeración. Los procedimientos legislativos abreviados contemplados en los Reglamentos son:

- Procedimiento de urgencia: Es el procedimiento más característico y general de los abreviados. En efecto, el desconcentrado en comisión, que también puede ser contemplado desde el prisma de la abreviación de trámites, tiene limitadas por el artículo 75.3 de la Constitución las materias sobre las que puede recaer; y el procedimiento de lectura única, contrario al anterior en cuanto que el trámite que suprime es el de comisión (mientras que en aquél es el de Pleno), debe aplicarse sólo, según los artículos 150 RC y 129 RS, a proyectos cuya "naturaleza lo aconseje o su simplicidad de formulación lo permita".

La tramitación urgente cabe, por el contrario, para cualquier proyecto o proposición de ley. Se trata además de un procedimiento de abreviación estrictamente temporal, en cuanto actúa exclusivamente sobre los plazos establecidos con carácter general para reducirlos a la mitad, sin supresión ni modificación de trámites. Su sencillez hace, por tanto, que sea el procedimiento abreviado más utilizado. A diferencia del procedimiento de lectura única, el de urgencia tiene apoyatura constitucional, pues es mencionado dos veces en la Constitución, en los artículos 86.3 (tramitación de los decretos-leyes convalidados como proyectos de ley por el procedimiento de urgencia) y 90.2 (reducción del plazo de tramitación de los proyectos en el Senado $)^{37}$.

Este procedimiento está configurado como procedimiento legislativo especial en el Reglamento del Senado (artículos 133-

y de la duración del procedimiento legislativo. Por el contrario, M. FRAILE CLIVILLÉS ("Prólogo" a M. ${ }^{a}$ A. GARCÍA MARTÍNEZ, El procedimiento legislativo, cit., pág. 13) considera esta imprevisión como objeción fundamental a nuestro procedimiento legislativo: la falta de un sentido ritual auténtico que facilite su comprensión y posible seguimiento por el pueblo y aun por los estudiosos e interesados en un proyecto, pues los elementos usuales y las fases procedimentales que tienen lugar lo hacen de una manera no controlada por el autor del proyecto y en ocasiones ni siquiera por la dirección del Parlamento (suscita al autor esta reflexión la regulación actual del debate de totalidad).

37 Discrepamos, pues, de la afirmación de RUIZ ROBLEDO de que el procedimiento de urgencia haya sido creado por los Reglamentos, elemento de distinción que utiliza en apoyo de la clasificación tripartita (A. RUIZ ROBLEDO, "Sobre los tipos de procedimientos legislativos", cit., pág. 661). 
135), lo cual es lógico, dada la incidencia que, conforme al artículo 90.3 CE, tiene la declaración de urgencia sobre la tramitación de textos legislativos en el Senado, cuya duración queda reducida a veinte días naturales ${ }^{38}$. La regulación reglamentaria introduce una drástica reducción de los plazos a lo largo del procedimiento y su cómputo en días naturales, además de facultar a la Mesa para acordar modificaciones en aquéllos.

El Reglamento del Congreso de los Diputados, como se ha señalado, regula la declaración de urgencia entre las disposiciones generales de procedimiento (Título IV, Capítulo sexto, arts. 9394), como un procedimiento (así lo califica el artículo 93.2) aplicable a la tramitación de cualquier asunto.

La declaración de urgencia tiene como efecto la reducción a la mitad de los plazos establecidos con carácter ordinario. Ahora bien, de una parte, se salva la facultad reconocida a la Mesa de la Cámara en el artículo $91 \mathrm{RC}$ de acordar la prórroga o reducción de los plazos; de otra, la escasa fijación de plazos para las distintas fases del procedimiento en el Congreso (apenas quince días para la presentación de enmiendas ${ }^{39}$, quince días ampliables para la elaboración del informe de la ponencia y dos meses, asimismo ampliables y escasamente observados, para la tramitación de cualquier asunto por una comisión - artículo 43.2 RC—) hace que la tramitación de un proyecto o proposición en el Congreso no tenga una duración fija o media. Por eso, como se ha apuntado, la reducción a la mitad de los plazos tiene consecuencias muy relativas en esta Cámara, aunque sí puede servir a la mayoría de la Mesa para apoyar la eventual denegación de la ampliación del plazo de enmiendas o a la mayoría pura y simple para justificar su inclusión apresurada en el orden del día del Pleno.

- Procedimiento de semiurgencia (Senado): La rigidez del procedimiento de urgencia en el Senado, en particular en cuanto al

38 Aunque, como señala la STC 234/2000 (en el conflicto entre órganos constitucionales sobre la declaración de urgencia del Proyecto de Ley sobre interrupción voluntaria del embarazo), el enunciado del artículo $90.3 \mathrm{CE}$ "pone de manifiesto que no constituye propiamente objeto del mismo la regulación de un procedimiento legislativo abreviado para la tramitación de proyectos normativos caracterizados por la urgencia", no existiendo en nuestro texto constitucional, a diferencia de otros, "un precepto que prevea el establecimiento de uno o varios procedimientos de tal carácter, por más que su completa regulación se remita a una norma de desarrollo". El Tribunal considera que el precepto citado se configura como uno de los varios preceptos constitucionales en los que se plasma la diferente posición que ocupan el Congreso de los Diputados y el Senado en el procedimiento legislativo ordinario, así como de las relaciones entre una y otra Cámara en el ejercicio de la potestad legislativa que el artículo $66.2 \mathrm{CE}$ residencia en las Cortes Generales (FJ 8).

39 Frente a la rigidez con que actúa el vencimiento de los plazos en el Senado, en la Cámara baja incluso se subsana la presentación tardía de enmiendas y votos particulares con la aquiescencia de todos los grupos a su tramitación, manifestada en la Junta de Portavoces. (Véase, por ejemplo, BOCG Congreso, Serie A, n. ${ }^{\circ} 4-9$, de 26 de noviembre de 2004 ). 
cómputo de los plazos en días naturales, hace que en ocasiones sea preferible optar por otro procedimiento abreviado, contemplado en el artículo 136 RS para cuando el proyecto no haya sido declarado urgente por el Gobierno o el Congreso de los Diputados (porque, en tal caso, el artículo 90.2 de la Constitución impone el procedimiento de urgencia).

Este procedimiento de semiurgencia reduce el plazo de tramitación de los proyectos y proposiciones a un mes, esto es, a la mitad del procedimiento ordinario, reduciéndose asimismo a la mitad los plazos intermedios. El cómputo de éstos en días hábiles (y no en naturales como en el procedimiento de urgencia) permite una cierta flexibilidad y sosiego en la tramitación, siendo particularmente útil cuando va a concluir un período de sesiones y se desea culminar la tramitación de proyectos antes de su finalización.

- Procedimiento de tramitación en lectura única. La aplicación de este procedimiento queda limitada por ambos Reglamentos a aquellos proyectos o proposiciones de ley cuya naturaleza lo aconseje o cuya simplicidad de formulación lo permita. La ambigüedad de esta determinación ha hecho que sea normalmente utilizado cuando existe un consenso tal sobre el contenido de un proyecto que hace prever que el texto no sea variado en el curso de la tramitación (sea o no simple su contenido), previo acuerdo de la Junta de Portavoces. Se emplea, pues, básicamente en tres casos:

1. Para la tramitación de proyectos o proposiciones de ley muy breves y sencillos, básicamente consensuados, que sería la previsión reglamentaria.

2. Para la tramitación de proyectos o proposiciones sobre los que recae acuerdo unánime de tramitación particularmente acelerada por urgencia política en la promulgación de la ley ${ }^{40}$. Estos proyectos o proposiciones han llegado a culminar su tramitación en una semana en cada Cámara, cuando existe una voluntad política en este sentido (por ejemplo, medidas para víctimas del terrorismo).

3. Cuando se opta por este procedimiento, o así lo impone una ley, por introducirse un elemento pactista en la elaboración del proyecto o proposición (por ejemplo, las modificaciones de la LORAFNA o los acuerdos sobre concierto y

40 Con excepciones que confirman la regla. Tal ha sido el caso de la tramitación por el procedimiento de lectura única del Proyecto de Ley Orgánica por la que se modifica la Ley 6/1985, de 1 de julio, del Poder Judicial, en relación con la provisión de cargos por el Consejo General del Poder Judicial, pese a la oposición del Grupo Popular (véanse Diarios de sesiones del Congreso, de 2 de diciembre de 2004, y del Senado, de 13 de diciembre de 2004). 
cupo económico en las Comunidades Autónomas de Navarra y País Vasco). Al menos el segundo caso (previsión legal) incide negativamente sobre la soberanía legislativa de las Cámaras.

El procedimiento de lectura única suprime totalmente la fase de comisión (incluido el informe de la ponencia), de forma que, tras el plazo de enmiendas, se produce un debate y votación en Pleno. Consigue por tanto la abreviación del procedimiento exactamente de forma contraria al procedimiento descentralizado en comisión, pues éste suprime la fase final del mismo, la aprobación por el Pleno, mientras que en la lectura única se suprimen las fases anteriores.

El procedimiento de lectura única es interpretado con mayor amplitud en la Cámara Baja, donde se admite la presentación y votación de enmiendas, aunque el Reglamento sólo contempla una votación de conjunto. En el Senado, la rigidez que introduce la prohibición de presentar enmiendas al articulado (únicamente se permite la presentación de propuestas de veto) hace en la práctica menos utilizado este procedimiento, porque impide cualquier mínima variación en el texto.

Concluimos nuestro estudio con un cuadro-resumen de los procedimientos legislativos en ambas Cámaras, tal como se desprende del análisis realizado.

1. Procedimiento legislativo ordinario

1.1. Aprobación por el Pleno

1.2. Aprobación delegada en comisión

2. Procedimientos legislativos especiales

2.1. En los Reglamentos de ambas Cámaras

- proyectos de ley de Presupuestos

- aprobación y reforma de los Estatutos de Autonomía

- proyectos de ley de armonización de disposiciones de las Comunidades Autónomas

2.2. En el Reglamento del Congreso:

- proyectos y proposiciones de ley orgánica

2.3. En el Reglamento del Senado:

- proyecto de ley del Fondo de Compensación Interterritorial

3. Procedimientos abreviados

3.1. En ambas Cámaras:

- procedimiento de urgencia

- procedimiento de lectura única

3.2. En el Senado:

- procedimiento de semiurgencia o de un mes 